\title{
Is RNA critical for the production of TSE infection?
}

\section{Jean-Guy Fournier*}

CEA/DSV/IMETI/SEPIA, Fontenay aux Roses, France

*Correspondence: jean-guy.fournier@cea.fr

\section{A commentary on}

Recombinant prion protein induces a new transmissible prion disease in wild-type animals.

by Makarava, N., Kovacs, G. G., Bocharova, O., Savtchenko, R., Alexeeva, I., Budka, H., Rohwer, R. G., and Baskakov, I. V. (2010). Acta Neuropathol. 119, 177-187.

Generating a prion with bacterially expressed recombinant prion protein. by Wang, F., Wang, X., Yuan, C. G., and Ma, J. (2010). Science 327, 1132-1135.

Mammalian prions generated from bacterially expressed prion protein in the absence of any mammalian cofactors.

by Kim, J., Kim, J. I., Cali, I., Surewicz, K., Kong, Q., Raymond, G. J., Atarashi, R., Race, B., Qing, L., Gambetti, P., Caughey, B., and Surewicz, W. K. (2010). J. Biol. Chem. 285, 14083-14087.

The prion hypothesis proposed by Prusiner (1998) stipulates that the causal agent of transmissible spongiform encephalopathies (TSEs) is composed exclusively of an infectious protein $\left(\mathrm{PrP}^{\mathrm{sc}}\right)$ produced after structural conversion of a cellular protein $\left(\mathrm{PrP}^{\mathrm{c}}\right)$. Recently, three studies attempting to test predictions arising from this hypothesis have been published by Makarava et al. (2010),Wang et al. (2010), and Kim et al. (2010).

Paying particular attention to the molecular composition of inocula inducing TSE disease reported in these investigations, I plan to discuss here, how these novel findings complement our previous results (Simoneau et al., 2009). In a pioneer work, we substantiated the idea that the requirement of a cofactor may be indispensable for the acquisition of converted recombinant prion protein (recPrP) infectivity. Our results indicate that this crucial cofactor extracted from $263 \mathrm{~K} \mathrm{PrP}^{\mathrm{sc}}$ is composed of two populations of small RNA having an average length of about 27 and 55 nucleotides. The association of these RNAs with recPrP reconstituted an infectious TSE agent showing in hamster brain strain characteristics slightly different from $263 \mathrm{~K}$ infectious agent (Simoneau et al., 2009).

As currently recognized, the demonstration of the prion hypothesis should be performed in wild-type (wt) animals. However I suggest that comprehensive proof of the causal agent of TSEs is composed exclusively of an infectious $\mathrm{PrP}^{\mathrm{sc}}$ protein can only be obtained when experimentation meets four requirements. This tetrad of rules is equivalent to Koch's postulates for microbial agents, namely that:

1. In vitro conversion of pure (e.g., recombinant) $\mathrm{PrP}^{\mathrm{c}}$ to $\mathrm{PrP}^{\mathrm{sc}}$ is required.

2. Experiments should be performed using wt animals.

3. Infected animals should develop fatal TSEs.

4. Transmissibility of the disease at the second passage should be demonstrated.

In the first study (Makarava et al., 2010) the authors inoculated different preparations of recPrP in hamsters. Though they use wt animals in accord with the second requirement, they fail to meet the first criterion. Indeed the key inoculum produced from a pure solution of recPrP fibrils remains innocuous, i.e., fails to cause disease. This recPrP is effective only if it is "activated" by an "annealing" process involving normal hamster brain homogenate (NHB). Other components may well have been incorporated from NHB. Moreover, the preparation induces a TSE-like disease only on second passage: the original inoculum did not have the ability to cause the TSE disease characterized at second pass; therefore the third condition is not met. Though a new scrapie agent has been created, the experimental context does not allow to know for sure that it is derived from converted recPrP alone.
Indeed, the inocula have had to undergo a long maturation step during the first passage (661 days). One could presume that converted recPrP, associated in a first step with endogenous RNA (present in NHB), is capable of inducing in the first brain the progressive synthesis of $\mathrm{PrP}^{\mathrm{sc}}$ and small RNA. The association ( $\mathrm{PrP}^{\mathrm{sc}}$-small RNA) we have reported (Simoneau et al., 2009) would form the infectious agent which inoculated in the second brain would induce overt TSE.

In a similar way to Makarava's work, the approach by Wang et al. (2010) of using wt animals to test the prion hypothesis is compromised by the incorporation of RNA into the inoculum. Infection is only achieved by adding some critical components to the recPrP solution, such as RNA (extracted from mouse liver) and synthetic phospholipid molecules, followed by a very extensive protein misfolding cyclic amplification (PMCA). The putative importance of the host RNA in this sophisticated preparation has not been explored or even debated. We must ask whether it is catalytic or not, imposing control on whether recPrP is associated or not with RNA. We can also ask what its molecular characteristics are: single or double stranded, short or long lengths and, eventually, what sequence? The role of RNA could be evaluated simply using inoculum containing recPrP without RNA.

The third study (Kim et al., 2010) used the classical PMCA reaction combined with $\mathrm{PrP}^{\mathrm{sc}}$ to convert recombinant PrP. Again the solution destined to be injected is not as the authors believe, of absolute recPrP purity. They used $\operatorname{PrP}^{s c}$ partially purified from $263 \mathrm{~K}$-infected hamster brain. In these conditions, native $\operatorname{PrP}^{\mathrm{sc}}$ is known to be highly contamined by nucleic acids particularly RNA a key factor for the acquisition of PMCA product infectivity (Geoghegan et al., 2007). On this basis, the crucial control would have been to assess the response of RNAse treatment on the preparative solutions. 
So the fundamental question as suggested by Supattapone (2010), is what phenomenon metamorphoses an innocuous recPrP preparation into an infectious one? It seems that a conversion step alone is not sufficient to obtain this objective. Rather, co-factors, RNA in some cases, appear to be necessary.

In conclusion, if one considers that the tetrad of rules that should be respected for a definitive demonstration of the prion hypothesis, ambiguities remain that should be clarified, with respect to the involvement of RNA.

\section{ACKNOWLEDGMENTS}

The author would like to thank Laura Manuelidis for her kind encouragements and express his sincerest gratitude to Robert
Somerville for discussions and his help in writing of the paper.

\section{REFERENCES}

Geoghegan, J. C., Valdes, P. A., Orem, N. R., Deleault, N. R., Williamson, R. A., Harris, B. T., and Supattapone S. (2007). Selective incorporation of polyanionic molecules into hamster prions. J. Biol. Chem. 282, 36341-36353.

Kim, J., Kim, J. I., Cali, I.,S Surewicz, K., Kong, Q., Raymond, G. J., Atarashi, R., Race, B., Qing, L., Gambetti, P., Caughey, B., and Surewicz, W. K. (2010). Mammalian prions generated from bacterially expressed prion protein in the absence of any mammalian cofactors. J. Biol. Chem. 285, 14083-14087.

Makarava N., Kovacs G. G., Bocharova O., Savtchenko R., Alexeeva I., Budka H., Rohwer R. G., and Baskakov I. V. (2010). Recombinant prion protein induces a new transmissible prion disease in wild-type animals. Acta Neuropathol. 119, 177-187.

Prusiner S. B. (1998). Prions. Proc. Natl. Acad. Sci. U.S.A. 95, 13363-13383.
Simoneau, S., Ruchoux, M. M., Vignier, N., Lebon, P., Freire, S., Comoy, E., Deslys, J. P., and Fournier, J. G. (2009). Small critical RNAs in the scrapie agent. Nature Precedings. Available at http://hdl.handle. net/10101/npre.2009.3344.1.

Supattapone, S. (2010). What makes prion infectious? Science 327, 1091-1092.

Wang F., Wang X., Yuan C. G., and Ma, J. (2010). Generating a prion with bacterially expressed recombinant prion protein. Science 327, 1132-1135.

Received: 06 May 2010; accepted: 06 July 2010; published online: 01 September 2010.

Citation: Fournier J-G (2010) Is RNA critical for the production of TSE infection? Front. Psychiatry 1:24. doi: 10.3389/fpsyt.2010.00024

This article was submitted to Frontiers in Neurodegeneration, a specialty of Frontiers in Psychiatry.

Copyright $\odot 2010$ Fournier. This is an open-access article subject to an exclusive license agreement between the authors and the Frontiers Research Foundation, which permits unrestricted use, distribution, and reproduction in any medium, provided the original authors and source are credited. 